\title{
A model to estimate road transport emissions from the entire life cycle
}

\author{
J. Lumbreras ${ }^{1}$, D. Ballarín ${ }^{1}$, J. M. López ${ }^{2}$, R. Villimar ${ }^{1}$, \\ B. Arenas ${ }^{2}$, F. Aparicio ${ }^{2} \&$ E. Rodríguez ${ }^{1}$ \\ ${ }^{I}$ Department of Chemical \& Environmental Engineering, \\ Technical University of Madrid (UPM), Spain \\ ${ }^{2}$ Vehicle Research Institute (Instituto de Investigación del Automóvil- \\ INSIA), Madrid, Spain
}

\begin{abstract}
Road transport is the most relevant source of Green House Gas (GHG) emissions in developed countries. To achieve global emission reductions in this sector it is necessary to take into account the life cycle of each technology. Therefore, policy makers need tools to compare policies and measures in terms of emissions in their life cycle.

In this study, a methodology to account GHG emissions from life cycle for a vehicle fleet (e.g. from a country, a company, a city, etc.) was developed. Moreover, a software tool called GlobalTRANS was designed and built to compute emissions from the fleet. It improves a previous tool called EmiTRANS that estimated only exhaust emissions (Tank-to-Wheel) incorporating Well-toTank and vehicle manufacturing emissions.

GlobalTRANS calculates and sums up emissions in terms of $\mathrm{CO}_{2}$ equivalent. Default coefficients have been calculated for Spain but this tool allows users to change the coefficients and substitute them.

Finally, the methodology has been successfully tested for the calculation of several fleets and pathways and results were compared with other Life Cycle Assessments (LCA). This paper presents an example from a diesel Euro 4 light duty vehicle showing that vehicle use means $79 \%$ of total emissions, while diesel production accounts for $13 \%$ and vehicle manufacture for $8 \%$.
\end{abstract}

Keywords: road transport, emissions, $L C A$, fuel, $\mathrm{CO}_{2}, G H G$. 


\section{Introduction}

Road transport, as the main source of Green House Gas (GHG) emissions in developed countries (EEA [1]), is the first challenge for the necessary change in economic model to achieve significant GHG emission reductions in the mid-term to reduce climate change (IPCC [2]). The efforts carried out to date (e.g. Euro standards in the European Union) are reducing emissions but they do not suppose a significant change in the transport model. In fact, GHG emissions in EU-27 have grown 30\% since 1990 and 7\% since 2000 (fig. 1) showing the lack of effectiveness of current efforts to reverse emission tendency. Freight transport by road is growing $2 \%$ per year while annual passenger road transport growth is $3 \%$.

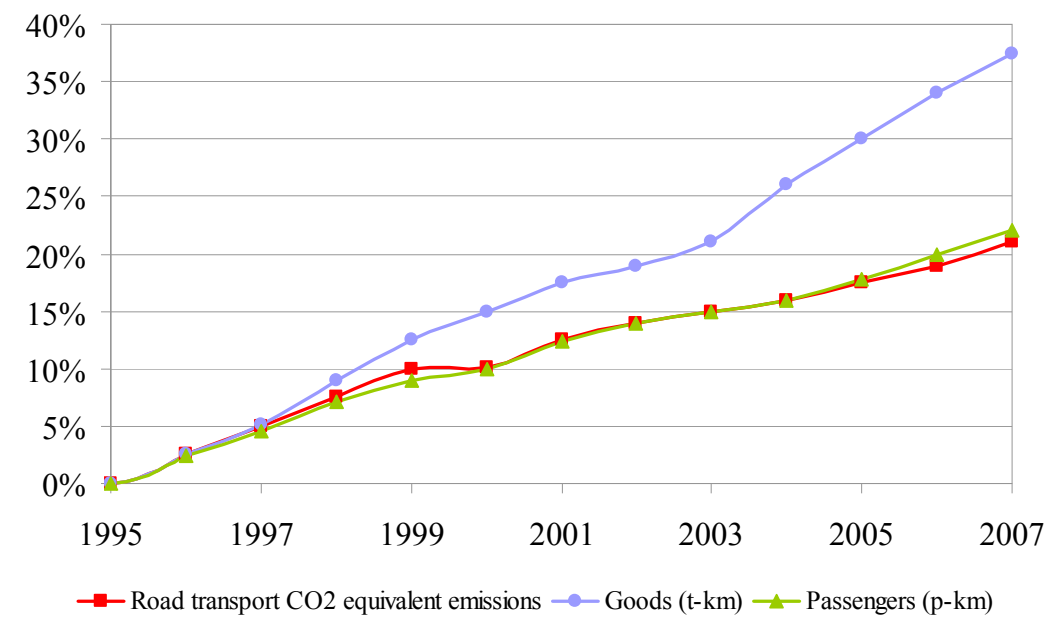

Figure 1: Past emissions, mobility, and freight transport trends in road transport for EU-27.

Moreover, road transport is also a human health problem that causes intense effects due to urban air pollution (Kampa and Castanas [3]). This effect is related to exhaust emissions that directly affect population. Consequently, to improve air quality is necessary a focus on emission exhaust.

However, climate change is a global problem (IPCC [2]) and should be managed accordingly. Considering only exhaust emissions gives a reduced analysis of the entire problem. Similarly, it is necessary to calculate not only $\mathrm{CO}_{2}$ emissions but also the other GHGs (which are methane and nitrous oxide for transport).

Therefore, it is necessary to implement policies and measures (P\&M) aimed at changing the existing model to reduce emissions. Nevertheless, when planning these P\&M is crucial to take into account emissions from the entire life cycle, otherwise solutions would only postpone or move the problem to other sectors and would not meet their target. To do so, decision tools incorporating Life 
Cycle Assessments (LCA) for each alternative are necessary to illustrate the policy makers and help them in the decision making process (Chatterton et al. [4]). In a similar way, companies could need tools to optimize or change their vehicle fleets to achieve their environmental objectives contributing to fighting against climate change.

Consequently, the aim of this paper is to develop a methodology to determine GHG emissions involved in the life cycle of vehicles in order to help decision makers in selecting the most effective policies and measures. A software tool called GlobalTrans has also been developed to facilitate calculations and database management.

\section{Methodology}

Lumbreras et al. [5] developed a methodology with a software tool called EmiTrans to quantify the effect of policies and measures in emission reductions from road transport. This methodology was focused on exhaust emission calculation for a vehicle fleet preparing Excel spreadsheets to be used by Copert 4 (Gkatzoflias et al. [6]).

GlobalTrans goes further, calculating GHG emissions from the entire cycle of a vehicle fleet. It considers emissions from vehicle manufacturing and scrapping, energy production and transportation (from Well to Tank) and energy use (from Tank to Wheel) considering energy as any type that vehicles can currently use (i.e. fossil fuels, biofuels, electricity, natural gas, Liquefied Petroleum Gases, and hydrogen). Accordingly to these calculations, the tool is structured in three modules for emission calculation covering each mentioned phase (modules 1-3) and another module to calculate emissions from energy mix for electricity production (module 0) as can be shown in fig. 2 .

Each module was developed separately as follows.

Module 1. Emissions from vehicle manufacturing and scrapping.

This module considers emissions from life cycle of vehicle materials. It comprises, for each material, from collection and process to waste management when the vehicle is definitely out of use. The main phases taken into account are:

1. Raw materials extraction and manufacturing

In this stage $\mathrm{CO}_{2}$ equivalent emissions due to the processing of materials comprising the vehicle are calculated, and they are expressed in $\mathrm{g} \mathrm{CO}_{2}$ equivalent $/ \mathrm{kg}$ of material used. Materials considered are: rubber, glass, steel, aluminium, liquids, copper, lead, plastics and others.

2. Vehicle manufacture and assembly

At this point, emissions due to generation of the electricity used in vehicle manufacturing and assembly are calculated by means of Module 0 which includes figures of $\mathrm{g} \mathrm{CO}_{2}$ equivalent emissions per $\mathrm{kWh}$ of electricity production. 


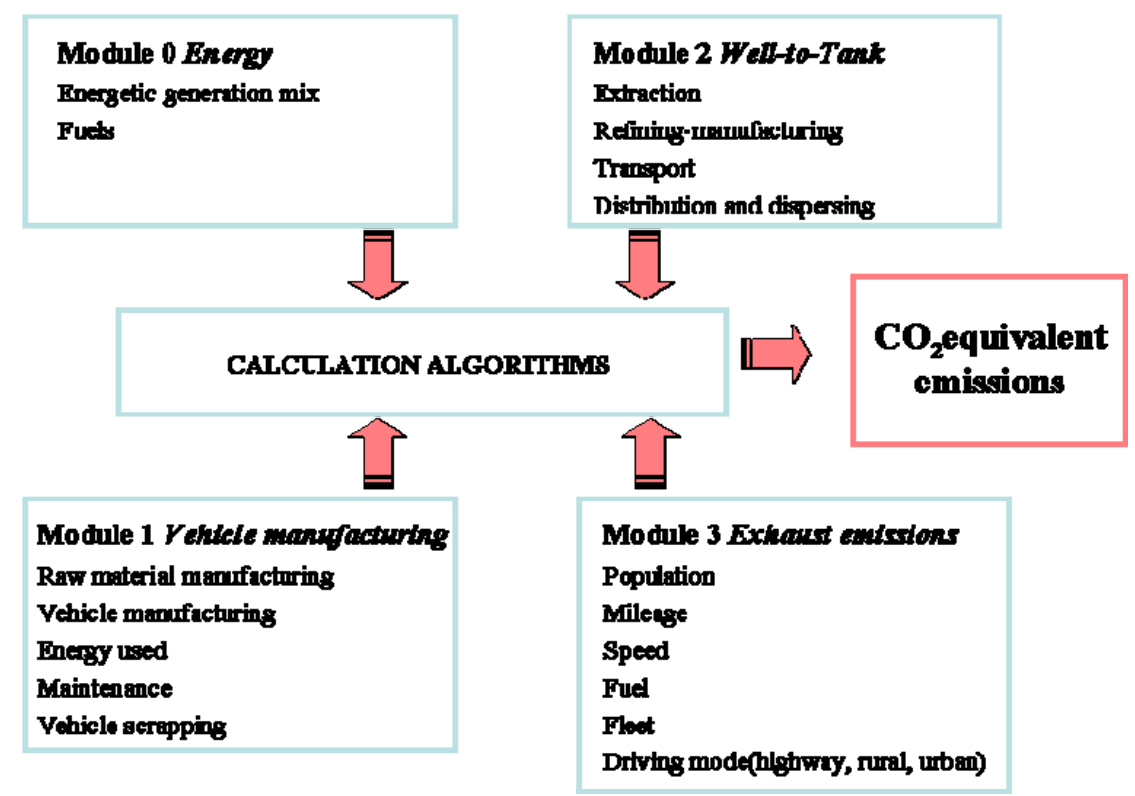

Figure 2: GlobalTRANS structure to estimate GHG emissions from the entire vehicle life cycle.

3. Vehicle maintenance

Emissions during vehicle maintenance processes are depend on thermal energy and electricity used to carry out them. These maintenance processes are calculated from mileage and vehicle weight data. Therefore, emissions of $\mathrm{g} \mathrm{CO}_{2}$ equivalent per $\mathrm{km}$ of vehicle mileage are given.

4. Waste management system (e.g. disposal, recycling, etc.).

At this stage, emissions of $\mathrm{CO}_{2}$ equivalent are given as a function of $\mathrm{kg}$ of disposed material taking into account different phases of vehicle scrapping and different materials comprising the vehicle.

The number of vehicles constituting the fleet is also taking into account in every stage to obtain $\mathrm{CO}_{2}$ equivalent emissions per vehicle considered.

Using GaBi-4 tool (GaBi Software website [7]) and comparing results with the most referenced study (IKP, 2003 [8]), two coefficients for each Copert4 vehicle class has been calculated. These coefficients comprise energy consumption and GHG emissions.

Module 2. Emissions from Well-To-Tank.

This module takes into account upstream emissions from energy source, so it incorporates emissions associated with the production of each fuel/source of energy considered. 
As a first step, a review of the state of the art of LCA has been done. The main works identified are the European EUCAR/JRC/CONCAWE [9] from 2006 and the U.S. GM WTW [10] from 2002.

The second step consists of defining the system limits (scope) and it was carried out consistently with the abovementioned studies. As a result, the following stages are consigned: fuel extraction, refining, and transportation to the petrol station. $\mathrm{CO}_{2}$ equivalent emission per energy unit $\left(\mathrm{g} \mathrm{CO}_{2} / \mathrm{MJ}\right)$ are given for each stage and for each fuel considered, as well as addition of all stages' emissions. Several fuels can be considered at this point: gasoline, diesel, natural gas, biodiesel, bioethanol, and LPG.

\section{Module 3. Emissions from Tank to Wheel.}

The third module is developed to provide exhaust GHG emissions from userdefined fleet. Copert-4 algorithms [11] have been used to estimate them.

In order to calculate GHG emission factors per vehicle according to these methodology, speed and operating life mileage values corresponding to each driving mode (highway, rural, urban) are necessary, as well as considered biofuels percentages with regard to global fuel consumptions.

\section{Module 0 . Electricity production}

Special treatment has been given to the electric sector. Electricity is used for vehicle manufacture, energy production and, in case of electric vehicles, for their use. Therefore, emissions from electricity production are necessary to add them on top of the WtW and vehicle manufacturing. To do so, a module was created with emissions per type of fuel use for electricity generation. In case of fossil fuels (i.e. natural gas, diesel, fuel oil, and coal) emission data from average plant type were used while no emissions are accounted for renewable energies (i.e. solar, wind, geothermal, etc.) and nuclear.

Construction and decommissioning of power plants and their waste treatments are not included in this tool due to variability and lack of comparable data (Lenzen [12]).

Default coefficients have been implemented in the preceding modules after a multidisciplinary expert decision, allowing user to replace them in case better information is available.

Calculation Algorithms.

After providing the necessary data, the tool generates GHG emissions for each selected module and the total amount (adding up figures resulting from the three modules).

\section{Application to Spain}

The developed tool has been applied to Spain in order to obtain both default values for other applications and a goodness check.

As an example, this paper shows emissions calculated for a diesel light duty vehicle weighting $1,817 \mathrm{~kg}$ that complies with the European emission standard Euro 4, and considering a total mileage of $250,000 \mathrm{~km}$ for its operating life 
Concerning module 1 , emission factors were calculated by means of data collected in GaBI-4 tool. Data for vehicle composition was obtained from the Spanish association for waste management from end of use vehicles (SIGRAUTO). GHG emissions for the considered vehicle add up to $9.91 \mathrm{t} \mathrm{CO}_{2}$ equivalent from which $54.9 \%$ are generated at the manufacturing stage. Electricity use in vehicle assembling and emissions associated to manufacturing constitute around $75 \%$ of total emissions from this module, as shown in Figure 3.

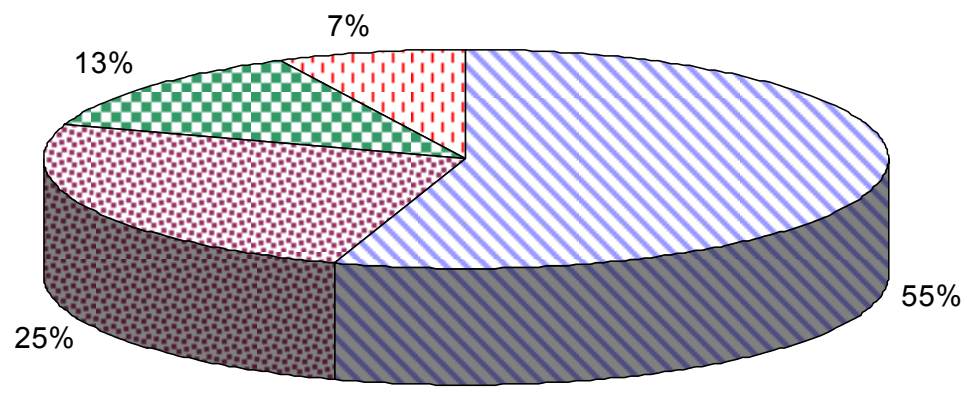

Raw material $⿴$ Electricity $\square$ Maintenance $\square$ Vehicle scrapping

Figure 3: GHG emission distribution for vehicle manufacturing.

With regard to module 2, coefficients were calculated considering data from the European EUCAR/JRC/CONCAWE study [9]. These values have been evaluated in order to apply them to the Spanish case, taking into account, for example, data on transportation distance for each energy source.

Total emissions obtained from GlobalTRANS for this module are $5.73 \mathrm{t} \mathrm{CO}_{2}$ equivalent. GHG emissions of this phase are mainly due to diesel produced in Spain which constitutes $73.6 \%$ of emissions. Imported diesel represents the $26.4 \%$ left. With regard to the contribution of different stages to total diesel Well-to-Tank emissions, $51.8 \%$ are due to fuel extraction and processing, $33.4 \%$ to refining, $7.7 \%$ to imported diesel transport by ship, and $7.1 \%$ to national diesel transport by pipeline. Emission distribution for Well-to-Tank stage is shown in Figure 4.

As for module 3, both Spanish research (Lopez et al. [13]) and Spanish emission inventory (MARM [14]) have been used to adequate emission factors to current Spanish fleet.

This module has a large number of variables that affect emissions. All of them have a default value in the tool. However, the user could introduce his own values (for instance, when most accurate data are available). As an example, in the Spanish case, we have used values for light duty diesel vehicles, incorporating Euro 4 technology, as shown in Table 1.

For this example, average emissions from the vehicle are $241 \mathrm{~g} \mathrm{CO}_{2 \text {-eq }} / \mathrm{km}$. GHG exhaust emissions produced during its operating life are $60.39 \mathrm{t} \mathrm{CO}_{2}$ equivalent. These emissions are mostly due to urban driving mode which 


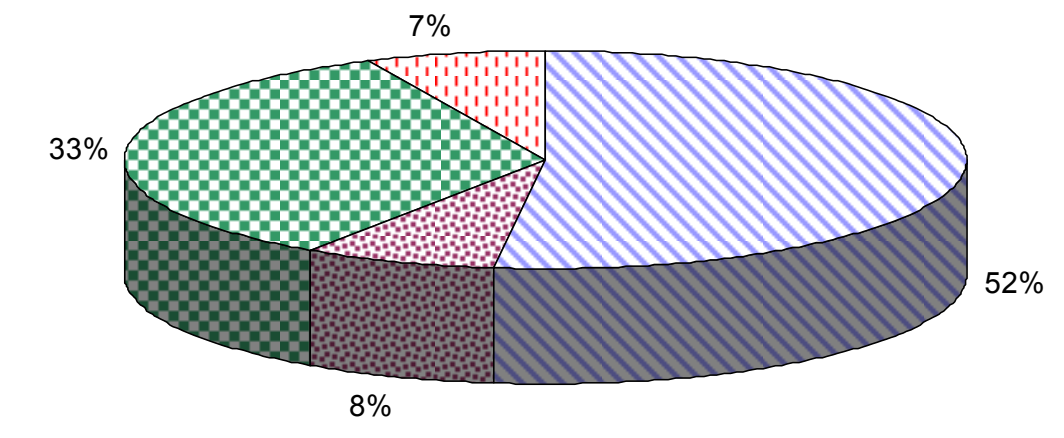

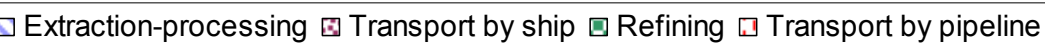

Figure 4: GHG emission distribution for well-to-tank.

Table 1: $\quad$ Example of values needed for exhaust emission calculation.

\begin{tabular}{|c|c|c|}
\hline Vehicle type & Parameter & Value used \\
\hline \multirow{4}{*}{\begin{tabular}{c} 
Euro 4, \\
diesel light \\
\cline { 2 - 3 } duty vehicle,
\end{tabular}} & Urban share & $50 \%$ \\
\cline { 2 - 3 } & Rural share & $21 \%$ \\
\cline { 2 - 3 }$<3.5 \mathrm{t}$ & Highway share & $29 \%$ \\
\cline { 2 - 3 } & Urban speed $(\mathrm{km} / \mathrm{h})$ & 25 \\
\cline { 2 - 3 } & Rural speed $(\mathrm{km} / \mathrm{h})$ & 65 \\
\cline { 2 - 3 } & Highway speed $(\mathrm{km} / \mathrm{h})$ & 100 \\
\cline { 2 - 3 } & Content of biodiesel & $5 \%$ \\
\hline
\end{tabular}

produces $54.3 \%$ of total emissions. $30.5 \%$ of GHG emissions are attributable to highway driving mode while the remainder $15.2 \%$ is due to rural driving (Figure 5).

The application of module 0 to Spain was done using electricity mix as presented in MITyC [15]. Main pathways related to power plants processes using several fuels, including different transportation modes, refine systems and distribution have been evaluated and computed in terms of energy and GHG emissions, and the most representative figures have been selected for the Spanish case.

Total $\mathrm{CO}_{2}$ equivalent emissions from the entire life cycle of the light duty vehicle analysed account to $76.034 \mathrm{t}$, from which $79 \%$ corresponds to the use phase (exhaust emissions, called Tank-to-Wheel), 13\% are due to vehicle manufacture and materials disposal and $8 \%$ are originated during the fuel production and transport (so called Well-to-Tank) as shown in Fig 6. 


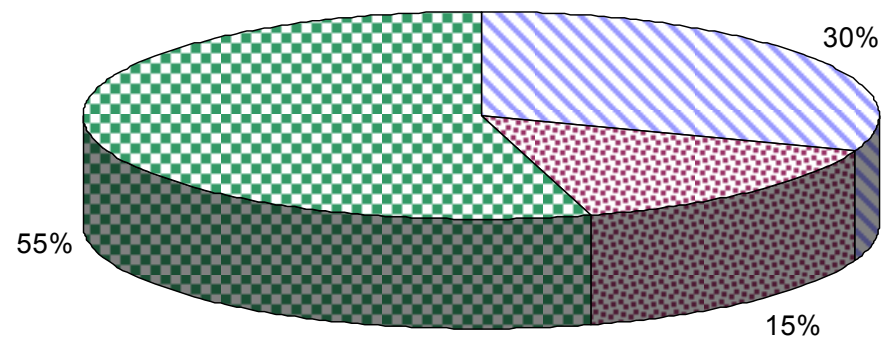

Highway driving mode 0 Rural driving mode $\square$ Urban driving mode

Figure 5: $\quad$ GHG emissions distribution for exhaust emissions.

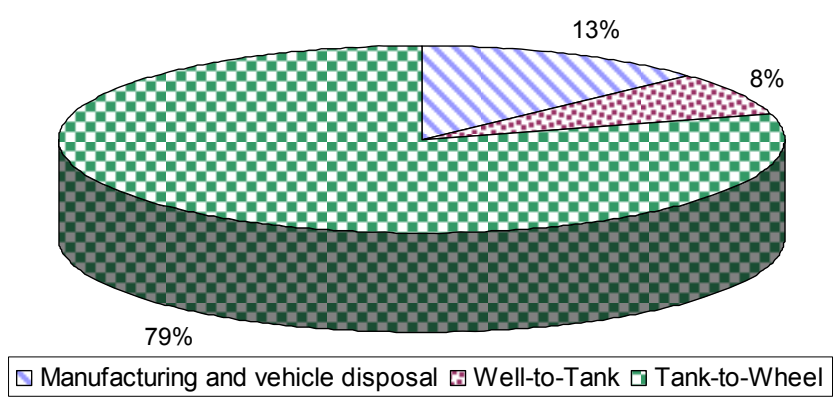

Figure 6: GHG emission distribution for a diesel Euro 4 light duty vehicle.

\section{Conclusions}

A software tool called GlobalTrans was developed to quantify GHG emissions from the entire life cycle of a vehicle fleet. This software allows policy makers and company managers to compare different alternatives for a vehicle fleet in terms of their GHG emissions.

The tool estimates emissions from vehicle manufacturing, energy production and transport, and energy use in the whole vehicle life considering both direct emissions and indirect linked to electricity consumption for each phase. Each of the considered phases is covered in a different module for better information management and transparency.

GlobalTrans incorporates default values for each module and vehicle type according to estimations done for the Spanish case. For the Tank to Wheel phase (exhaust emissions), default values are taken from Copert 4. Default values existence allows the user to obtain emissions from a fleet with only the number of vehicles for each technology. 
The tool was satisfactory applied to Spain. Results shown in this paper demonstrate its applicability and the importance of considering not only exhaust emissions when calculating emissions from a vehicle fleet. That is, non-exhaust emissions corresponding to vehicle manufacturing and disposal and fuel production and transportation mean $21 \%$ of the entire life cycle emissions.

\section{References}

[1] European Environment Agency. Greenhouse gas emission trends and projections in Europe 2009. Tracking progress towards Kyoto targets, 2009.

[2] Metz B., Davidson, O.R., Bosch P.R., Dave R., Meyer L.A. (eds). Contribution of Working Group III to the Fourth Assessment Report of the Intergovernmental Panel on Climate Change, 2007. Cambridge University Press, Cambridge, United Kingdom and New York, NY, USA, 2007.

[3] Kampa, M., Castanas. E., 2008. Human health effects of air pollution. Environmental Pollution 151, 2008, Pages 362-368.

[4] Chatterton T.J., Coulter, A., Musselwhite, C., Lyons, G., Clegg, S., 2008. Understanding how transport choices are affected by the environment and health: Views expressed in a study on the use of carbon calculators. Public Health 123 (2009) e45-e49.

[5] Lumbreras, J., Valdés, M., Borge, R., Rodriguez, M.E., 2008. Assessment of vehicle emissions projections in Madrid (Spain) from 2004 to 2012 considering several control strategies. Transportation Research Part A 42 (2008) 646-658.

[6] Gkatzoflias, D., Kouridis, C., Ntziachristos, L., Samaras, Z., 2007. COPERT 4, Computer Programme to Calculate Emissions from Road Transport. Aristotle University Thessaloniki/European Environment Agency (2007) [http://lat.eng.auth.gr/copert/].

[7] GaBi Software website, www.gabi-software.com

[8] IKP-Institute for Polymer Testing and Polymer Science of the University of Stuttgart and PE Europe GmbH, 2003. IKP-Institute for Polymer Testing and Polymer Science of the University of Stuttgart and PE Europe GmbH (2003). GaBi 4 software [http://www.gabi-software.com/].

[9] EUCAR/JRC/CONCAWE, 2008. Well-to-Wheels analysis of future automotive and powertrains in the European context, Version 3 (2008).

[10] Choudhury, R. 2002. General Motors, Well-To-Wheel Analysis of energy use and greenhouse gas emissions of advanced fuel/vehicle systems- a European study. L-B-Systemtechnik GmBH (2002).

[11] COPERT4 Software website, http://lat.eng.auth.gr/copert/

[12] Lenzen, M. 2008. Life cycle energy and greenhouse gas emissions of nuclear energy: A review. Energy Conversion and Management 49 (2008) 2178-2199.

[13] López, J.M., Gómez, Á., Aparicio, F., Sánchez, F.J., 2008. Comparison of GHG emissions from diesel, biodiesel and natural gas refuse trucks of the city of Madrid. Applied Energy volume 86, number 5, pages 610-615 (2009) 0306-2619. 
[14] Spanish ministry of Environment and Rural and Marine Affairs (MARM), 2007. Spain's Emission Inventory. CORINE-AIRE 1990-2006. Report of the Ministerio de Medio Ambiente y Medio Rural y Marino, Madrid (2008).

[15] Ministerio de Industria, Turismo y Comercio, 2008. La Energía en España 2008. ISBN:978-84-96275-86-7. 